TAO, Vol. 13, No. 4, 523-545, December 2002

\title{
Reduction in Sunshine Duration over Taiwan: Causes and Implications
}

\author{
Shaw Chen Liu ${ }^{1,2, *}$, Chung-Ho Wang ${ }^{1}$, Chein-Jung Shiu ${ }^{3}$, \\ Hsiu-Wu Chang ${ }^{4}$, Chang-Keng Hsiao ${ }^{4}$, and Shuh-Haung Liaw ${ }^{4}$
}

(Manuscript received 14 December 2001, in final form 29 November 2002)

\begin{abstract}
Long-term records (about 100 years) of meteorological parameters of Taiwan have been analyzed to study causes and implications of decreasing trends in sunshine duration observed during Taiwan's rapid economic developing period that started in the 1960's. Although the largest decreasing trends in sunshine duration are found in major urban centers, in-depth analysis shows that the reductions are surprisingly uniform and well correlated among stations throughout Taiwan and her surrounding islands, implying that direct scattering by aerosols is not the major cause of the reductions. Similar reductions occur at two high altitude stations, namely Alishan $(2.4 \mathrm{~km})$ and Yushan $(3.85 \mathrm{~km})$, suggesting that the cause of the reductions is at altitude above $3.85 \mathrm{~km}$. After eliminating other potential causes, we hypothesize that the trends are most likely caused by an increase in regional clouds and/or cloud albedo as a result of increased anthropogenic aerosols. The extent of the region depends on the season. Strong westerlies above $3.85 \mathrm{~km}$ in winter and spring imply that southern China, Southeast Asia, India and regions further upwind may suffer similar reductions and could be the major source of anthropogenic aerosols. In summer and fall, the wind pattern indicates Taiwan's own emissions of aerosols can play a significant role in the reduction. Potential ramifications of the increase in clouds/cloud albedo to regional climate change are serious. The increase in clouds/cloud albedo obviously has lead to a decrease in the diurnal temperature range. These changes may also be linked to an increase in precipitation intensity and other observed changes in some key climate parameters in Taiwan.
\end{abstract}

\footnotetext{
${ }^{1}$ Institute of Earth Sciences, Academia Sinica, Taipei, Taiwan

${ }^{2}$ Department of Atmospheric Sciences, National Central University, Chung-Li, Taiwan

${ }^{3}$ Department of Atmospheric Sciences, National Taiwan University, Taipei, Taiwan

${ }^{4}$ Central Weather Bureau, Taipei, Taiwan

* Corresponding author address. Dr. Shaw Chen Liu, Institute of Earth Sciences, Academia Sinica, P.O. Box 1-55, Nankang, Taipei, Taiwan, ROC; E-mail: shawliu@earth.sinica.edu.tw
} 
(Key words: Sunshine duration, Aerosols, clouds, Precipitation and regional climate)

\section{INTRODUCTION}

Aerosols can perturb atmospheric radiation through a direct effect of scattering and absorption of radiation, and an indirect effect via interaction with clouds. By acting as cloud condensation nuclei (CCN), possible effects of anthropogenic aerosols on the physics and chemistry of clouds have been hypothesized and observed under various ambient conditions (Wamer and Twomey 1967; Twomey 1974; Changnon 1981; Coakley et al. 1987; Radke et al. 1989; Liou et al. 1990; Liepert 1997; Rebetez and Beniston 1998). Warner and Twomey (1967) observed significant increases in CCN concentrations below bases of cumulus clouds and increases in cloud droplets above their bases downwind of fields of burning sugar canes. They hypothesized that the large number of anthropogenic CCN could generate smaller cloud droplets and slow down collision and coalescence growth of precipitation. Twomey et al. (1984) further proposed that anthropogenic aerosols could increase the lifetime of clouds, increase cloud albedo, and affect the radiative budget of the atmosphere. Coakley et al. (1987) and Radke et al. (1989) examined satellite imagery and aircraft observations of ship trails, respectively, and found enhanced brightness, higher droplet concentrations, smaller droplet sizes, and higher liquid water content than surrounding clouds. Increase in high-level clouds as a result of aircraft emissions of $\mathrm{CCN}$ has been demonstrated in recent works using various sets of observations (Liou et al. 1990; Frankel et al. 1997; Buocher 1998, 1999; and Minnis et al. 1998). Furthermore, Changnon.(1981) and Liepert (1997) hypothesized that the long-term (over most of the last century) increasing trends in high clouds were the cause of concurrent decreasing trends observed in sunshine duration over the US and Europe.

Recent investigation by Rebetez and Beniston (1998) is particularly interesting as it attempted to relate long-term trends of low-level clouds on the regional scale (over Switzerland) to increasing surface emissions of anthropogenic aerosols. Through an analysis of Swiss climatological data in the $20^{\text {th }}$ century, they found that changes in sunshine duration at low altitude stations were strongly correlated with changes in daily temperature range (DTR). The changes in sunshine duration were negative (decrease) in summer months, May and February, but positive or little change for other months. Meanwhile, changes in DTR of individual months were always negative. In contrast, at high elevations (above $1500 \mathrm{~m}$ ), changes in both sunshine duration and DTR were highly scattered and thus the correlation was absent. The authors suggested that the changes in sunshine duration and in DTR were the result of corresponding changes in low clouds. They further suggested that the changes in low clouds were caused by either changes of anthropogenic aerosols or atmospheric water vapor, or a combination of both. While their suggestions were plausible, the authors left open a key question: the puzzling point that the changes in sunshine duration had different signs for different months.

In the last four decades, Taiwan experienced an extraordinary rapid economic development that saw an increase of about 20 times in energy use. In fact, both the current energy use and emissions of air pollutants (including aerosols) per unit area in Taiwan are the highest among countries with population 10 millions or more. With such a high current value and a large dynamic range over a relatively short period in the anthropogenic emissions of air 
pollutants, Taiwan presents an excellent opportunity for examining and testing the hypothesis of possible effects of anthropogenic aerosols on atmospheric radiation, and in turn, on the regional climate.

In this work, we analyze long-term records (about 100 years) of meteorological parameters of Taiwan to study possible effects of anthropogenic aerosols on the sunshine duration, DTR, clouds, and other parameters of regional climate. We will focus on the relatively large changes in sunshine duration observed since 1960's and discuss possible causes and implications.

\section{DATA}

Data from eight Taiwan meteorological stations operated by the Central Weather Bureau (CWB) with records dated back to 1910 or earlier are used as the basis for analysis of longterm trends. Figure 1 shows the locations of these stations. Three stations (Taipei, Taichung, and Tainan; crosses) are located in major urban areas. Hualien and Taitung are two small cities in the east coast. Hengchun is a small town near the southern tip of Taiwan and is a clean station. This is substantiated by the lowest concentrations of PM10 observed among the 70 plus monitoring stations operated by Taiwan EPA over the island. In fact, atmospheric concentration of PM10 usually gets below the detection limit of the instrument (about $12 \mu \mathrm{g} / \mathrm{m}^{3}$ ) in summer when maritime air from the southwest prevails. It is known that PM2.5 is more relevant than PM10 in addressing the optical property of aerosols. However, there is no routine PM2.5 measurement in Taiwan, experimental measurements of PM2.5 at a few stations show that PM2.5 aerosols are usually proportional to PM10, but have a smaller difference in concentrations between urban centers and rural areas, probably because of their longer lifetime. Penghu and Pengchiayu are both located on off-coast islands where local anthropogenic emissions are negligible. These two stations are rarely affected by pollution from Taiwan except in the summer half of the year when the prevailing wind is weak and thus there is some probability of Taiwan's pollutants drifting over the stations. Even then, the influence of pollution from Taiwan over the two islands should be limited. This is evident by the analysis of MODIS satellite atmospheric optical depth (AOD) data that shows a factor of three or higher AOD over the polluted western plain than those over the ocean and eastern Taiwan through most of the year ( $\mathrm{Li} 2002)$.

In winter and spring the entire region around Taiwan is frequently under the influence of relatively strong northeasterly monsoon winds driven by the high pressure system over the Asian continent. The monsoon first drives continental outflow (including air pollutants and dust) from northern China southeastward to East China Sea and then turned southwestward to Taiwan. Thus the continental outflow may have a significant impact on the levels of air pollutants at stations with little local emissions in winter and spring, e.g. Penghu and Pengchiayu. AOD over the ocean measured from satellite (Husar et al. 1997) shows a clear spring maximum around Taiwan as a result of Asian dust storms. In the summer, the AOD levels are more than a factor of two lower than those of spring, especially in the southeastern side of Taiwan.

Over the years, the number of meteorological stations has gradually increased to 25. Data from these later stations are included in a more detailed analysis of the trends after 1960. The 


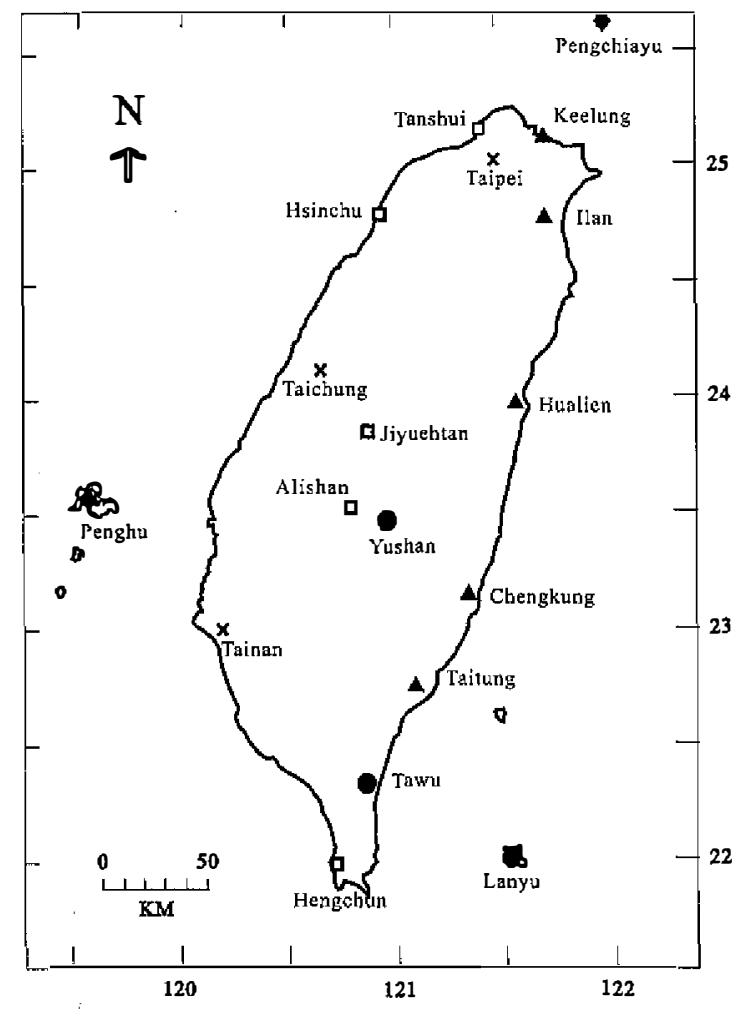

Fig. 1. Locations of meteorological stations in Taiwan used in this study. The three major urban centers are shown by crosses, medium coastal cities and rural stations in western Taiwan by open squares, small and medium cities on the east and northeast coast by solid triangles, and off-coast island sites by solid diamonds, other stations are discussed in the text.

locations of these stations are also shown in Fig. 1. Changing the instrument of sunshine duration measurements is a great concern in the analysis of trends. Fortunately, only two (Hualien and Hengchun, from Compbell-Stokes instrument to Jordin in 1971) of the eight long-term stations, and only six of the 25 stations, changed their instruments during the crucial period of 1960 to 1990 when large trends were detected. Furthermore, inter-comparisons through concurrent measurements were conducted when instrument was changed. Three types of instrument have been used. Currently, EKO Lotary instrument which has a self-contained calibration system is used at all stations. Compbell-Stokes was the primary instrument used during the important period of 1950 to 1991. Before 1950, most of the stations used Jordin instrument. The latter two instruments were not calibrated other than the inter-comparisons during concurrent measurements with the EKO Lotary instrument. All three types of instrument measure the direct solar radiation. They are not sensitive to the diffuse light. Thus, measurements from these instruments can be considered as a measure of the total optical depth of light scattering and absorption materials along the line of sight, including clouds, aerosols, and gases.

The Compbell-Stokes instrument employs a glass sphere to focus the sun's rays to an intense spot, which will char a mark on a curved card mounted concentrically with the sphere. As the earth rotates, the position of the spot moves across the card and a trace is charred. When the sun is obscured, the race is interrupted. At the end of the day the total length of the trace, less gaps, is proportional to the duration of sunshine. A major problem with the CompbellStokes instrument is that the card tends to get wet after showers and does not char properly 
afterward.

Obviously, the observed long-term trends of sunshine duration depend critically on the precision of the instrument. The precision depends not only on the quality of the instrument, but also on the maintenance and operation of the instrument. In fact, our evaluation suggests that the latter is by far the major factor determining the precision. We'll present evidence later that there is an objective method to evaluate the short-term (a few years) precision of the instrument. Long-term (more than 10 years) precision, however, is more difficult to evaluate.

It is well known that measurements of clouds are semi-quantitative and tend to be subjective as they are done by an observer's visual evaluation of the cloud cover. This makes it difficult to derive from the measurements any reliable long-term trends of clouds on the order of $10 \%$ level discussed in this work.

\section{RESULTS}

Figure 2 shows the average yearly sunshine duration of the all eight long-term stations from 1898 to 1999 . Also shown are the five-year running average values. The zero line with value of 2043 sunshine hours (one sunshine hour is defined as an hour of direct solar radiation $>120$ watts $/ \mathrm{m}^{2}$ ) is drawn to provide a visual guideline to highlight the trends in recent years. The most remarkable feature in Fig. 2 is a large reduction after about 1970. The last five-year (1995-1999) average sunshine hours are about 16\% below the mean value. We note that the large reduction after 1970 occurred at all eight stations. Six of the eight stations had similar reductions in magnitude (within 15\% of the average reduction) and all eight stations had similar patterns in their reductions. Given the fact that three different instruments were used and

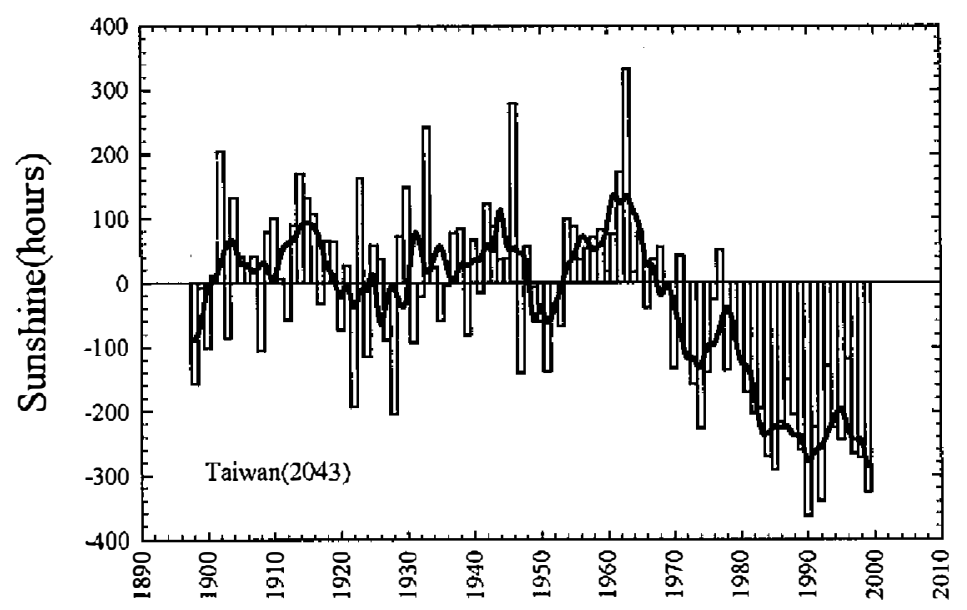

Fig. 2. Average annual sunshine duration observed at eight long-term stations (vertical bars). The horizontal zero line is drawn arbitrarily as a visual guideline to highlight the trends in recent years. The value of the zero line (2043) is shown inside the parentheses. The solid profile represents five-year running mean values. 
there was no calibration until 1991 when EKO Lotary instruments were installed, the consistency in the reductions is surprising good, suggesting that they are significant and credible.

The large reduction after 1970 is significantly greater than any deviation from the mean in the years prior to 1960 . For example, the reduction from 1945 to 1951 is only $5.2 \%$. Therefore, it is highly unlikely that the large reduction in recent years is part of any natural variability. Moreover, when Fig. 2 is compared to the total fossil fuel combustion in Taiwan (Fig. 3), it is immediate noticeable that the large reduction in the last 30 years coincides with the drastic increase in the fossil fuel combustion, the predominant source of air pollutants. In fact, even the leveling off of the reduction in the 1990's is consistent with the gradual improvement in the pollution of total suspended particulate matter (i.e. aerosols) since late 1980's as a result of reduced emission of SO2, a major precursor of aerosols (EPA 2000). In this regard, we note that the leveling off could also be interpreted as the level of aerosols at which their effect on sunshine duration reaches a saturation point.

It is necessary to point out that there is some uncertainty in determining the starting time of the large reduction in the sunshine duration because of the natural variability. Without any quantitative knowledge of the natural variation around the starting time, a straightforward approach to determining the starting time is to take the intersection of the sunshine duration profile and the mean. When the natural variability is taken into consideration, any year between 1960 to 1974, in which the difference from the mean is less than 2 standard deviations, has a reasonable probability to be the starting time. The starting time affects the magnitude of the reduction significantly. For example, the reduction would be $20 \%$ and $11 \%$, respectively, for starting times of 1960 and 1974. Obviously the starting time also affects how well the emission pattern of air pollutants matches the large reduction. Finally, assuming air pollutants are responsible for the reduction, the starting time would represent the levels of air pollutants at which their effect on the sunshine hours starts to be detectable.

The close match/correlation between the large reduction and the increase of air pollutants, although suggestive, does not prove any causal relationship between them. More evidence is needed. In the following, we examine the spatial variations of the sunshine duration observed at all 25 stations. We will show that the spatial variations of the changes in sunshine duration

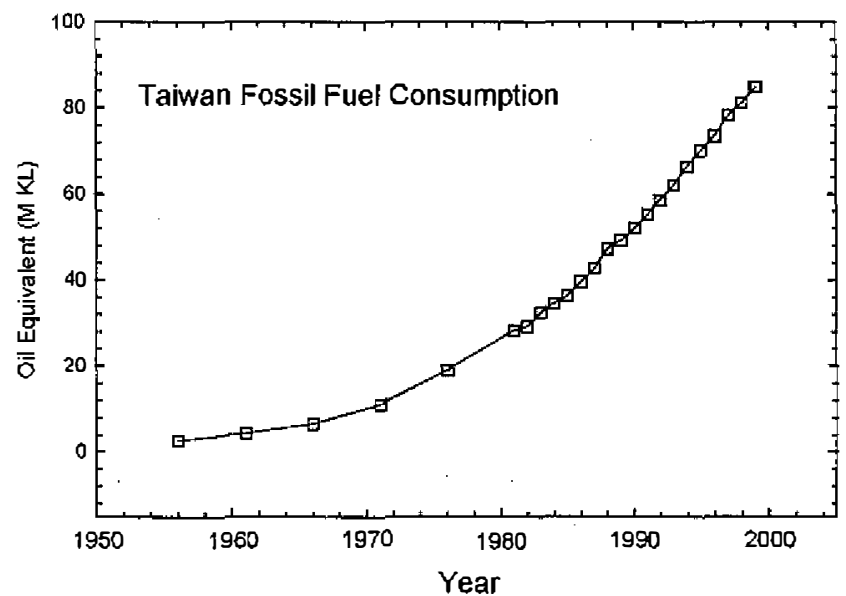

Fig. 3. Annual fossil fuel consumption in Taiwan. 
is consistent with the notion that cloud cover and/or cloud albedo have increased over Taiwan due to a regional scale increase in anthropogenic aerosols.

Figures 4a-d show the yearly and seasonal averages (bars) of the sunshine duration for four different spatial regimes, respectively. Also shown are their five-year running average profiles (solid lines). The four regimes are: major urban centers in western Taiwan ( 3 stations, crosses), medium coastal cities and rural stations in westem Taiwan (5 stations, open squares), small and medium cities on the east and northeast coast (5 stations, solid triangles), and offcoast island sites ( 2 stations, solid diamonds). An extremely high elevation station, Yushan at $3.85 \mathrm{~km}$, will be discussed separately. In addition, Tawu and Lanyu stations will also be discussed separately because their trends are qualitatively different from trends of the above

(a)

Group A

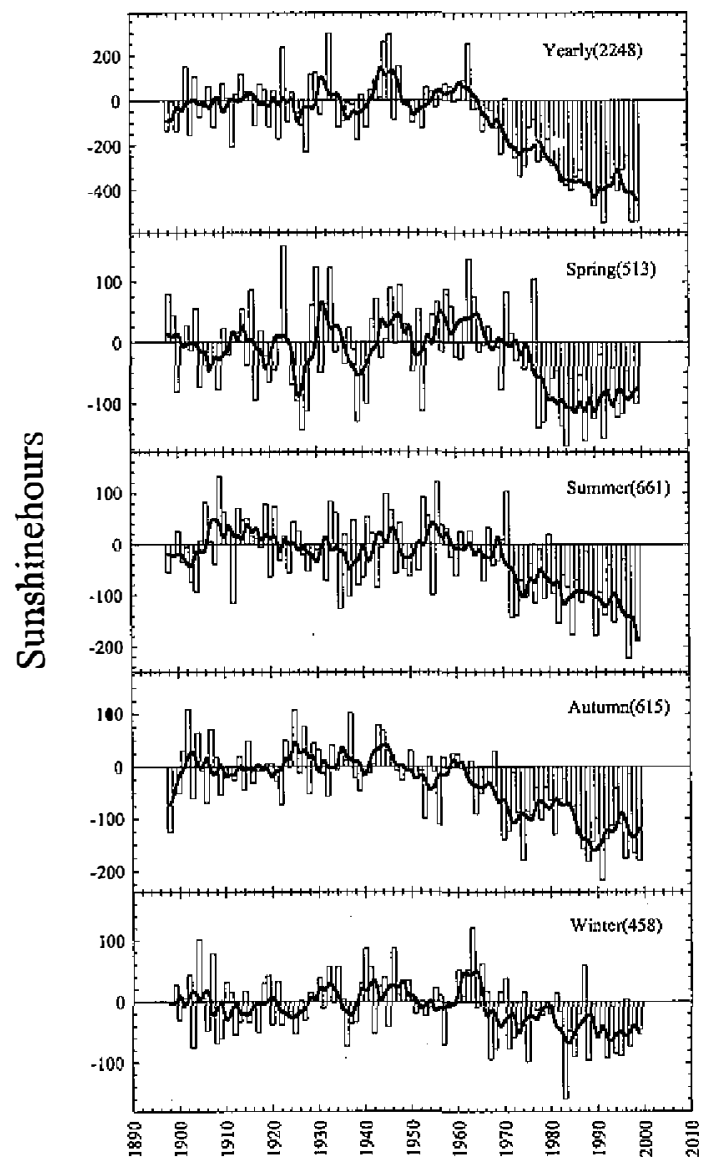

(b)

\section{Group B}

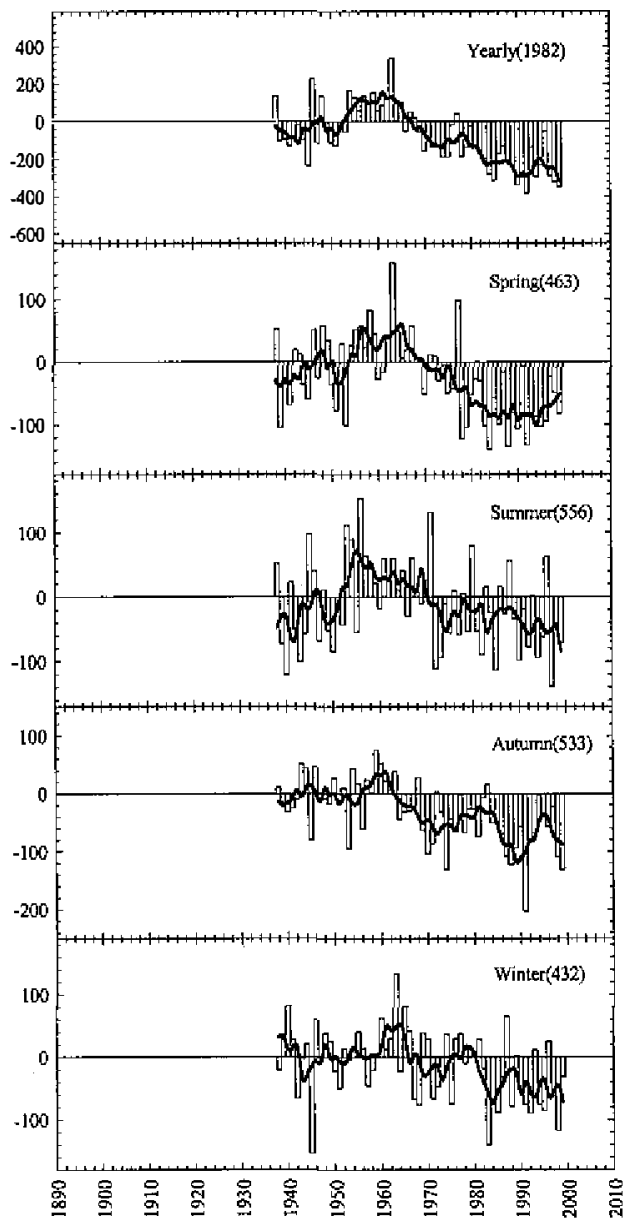

Figs. 4a-d. Annual and seasonal averages of sunshine duration observed in four different regimes described in the text, respectively. Symbols are the same as those in Fig. 2. 
(c)

Group C

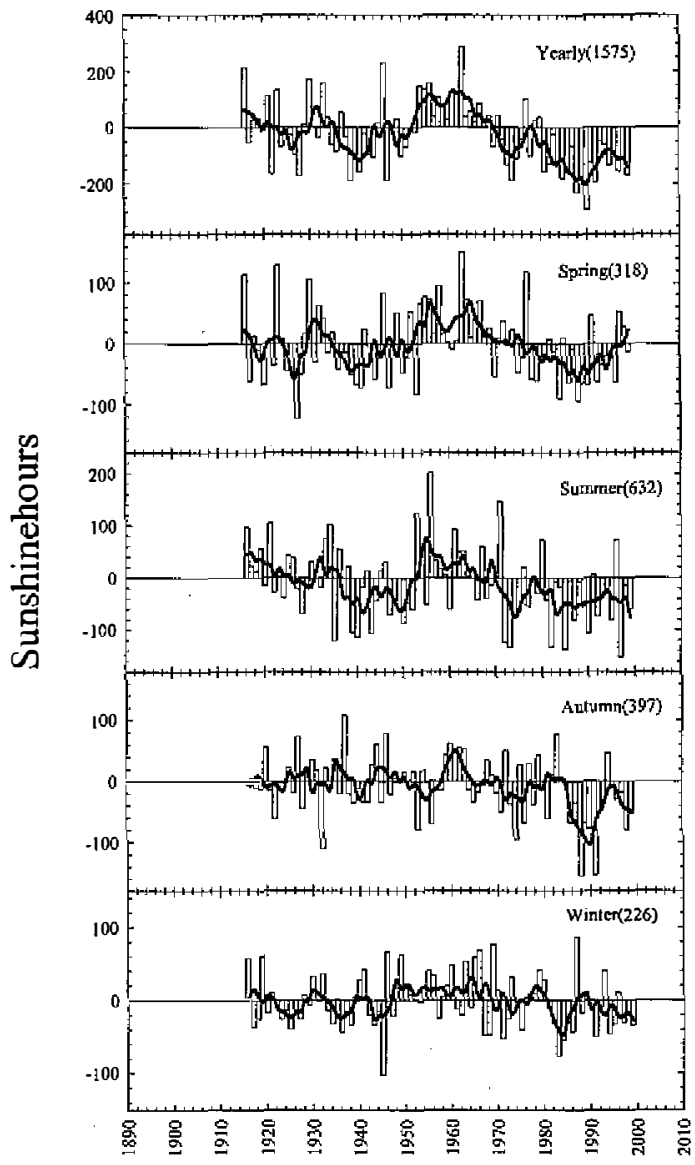

(d)

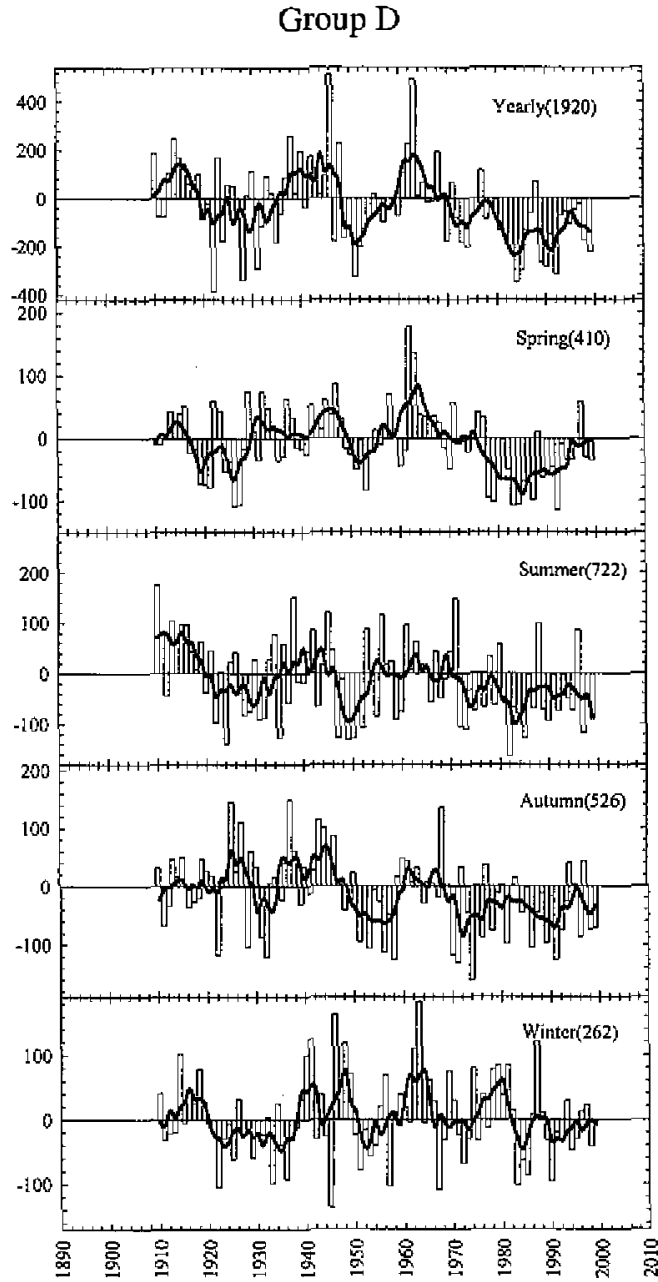

(Fig. 4. continued)

16 stations. All together 18 stations will be examined out of a total of 25 . Reasons of excluding the other seven stations are their short observation records ( 6 stations) and change of observation procedure (1 station).

Criteria used to categorize the four regimes are emissions of air pollutants, prevailing winds, as well as geological environments. More than $95 \%$ of the emissions occur over the western part of Taiwan where practically all flat lands and major urban centers exist. The eastern part of Taiwan is separated from the west by the Central Mountain Range in northsouth direction with an average elevation of about $2.5 \mathrm{~km}$. The first regime is obviously the most polluted among the four. The second regime is next in terms of pollution level because of widespread regional emissions. The stations in the east and northeast coast are relatively clean. Their concentrations of PM10 are generally about a factor of two lower than those over western Taiwan. In addition, they are located in relatively small coastal cities that, in terms of 
direct air pollutant influence, are isolated from each other and the rest of Taiwan, especially during the summer half of the year when winds are usually calm. During winter and early spring, as discussed earlier, Taiwan is dominated by the northeasterly monsoon. Therefore, it should be extremely interesting to examine the seasonal variation of the trends of sunshine duration.

The yearly as well as seasonal patterns of the four different regimes show many remarkable similar features. For example, there was a small yet discernable "recovery/increase" of yearly sunshine duration in mid-1990's in all four regimes. This recovery/increase was closely related to a conspicuous dip near 1990 that occurred most clearly in autumn in all four regimes. Another example was that similar seasonal variations (not the absolute value) showed up in every regime, especially after about 1960 . We note that even very small features such as the small changes in the 5-year running average of the summer profiles between 1986 and 1996 were similar in both shapes and magnitudes (as small as about 15 hours of sunshine duration) in every regime. Moreover, the similarity in shapes and magnitudes also exist among individual station (not shown). These similarities/consistencies are important and reassuring because they imply that both the general patterns and the small features are statistically significant. More importantly, they provide an independent check on the precision (not absolute accuracy) of the insument at each of the stations because the instruments must have the precision needed to detect the similarities/consistencies. For instance, the 15 sunshine hours cited above correspond to $2.9 \%, 2.3 \%, 2.4 \%$, and $3.3 \%$ of the total sunshine hours for spring, summer, autumn, and winter of the first regime, respectively. Because the stations made the measurements independently, the instruments of these stations must have precisions significantly better than $2.3 \%$ in order to detect and reproduce consistently the features of 15 sunshine hours.

Another independent method of estimating the precision of the instrument is to examine the relationship between the sunshine duration and the precipitation. The two are expected to be anti-correlated because the precipitation is proportional to the amount of clouds when averaged over a long period time (on the order of a year). Figure 5 compares the sunshine duration to the precipitation for the eight long-term stations. The two profiles show a significant strong anti-correlation except the gradual reduction of sunshine duration after about 1970. The strong anti-correlation reconfirms the notion that the annual precipitation is a good measure of the annual amount of clouds, and the sunshine duration is controlled primarily by the amount of clouds. More importantly, as the precipitation and sunshine duration are measured by two independent techniques, the existence of consistent anti-correlation down to small features/ changes is a strong evidence of the precisions of both measurements at the levels of those features/changes. In other words, the two measurement techniques must have the precisions to detect those features/changes. Quantitatively the anti-correlation occurs consistently for small changes down to around 15 sunshine hours, thus we can conclude that on relatively short-term basis (a few years) the instruments have the precision better than 15 sunshine hours or about $2 \%$.

In regard to the long-term drift in the precision of instrument, we note that the period of 1960 to 1999 includes three types of instrument. Since it is highly unlikely that different types of instruments to have similar drift in long-term precisions, the consistent similarity in longterm changes (i.e. decreases) at different stations after 1960's implies that the long-term changes 


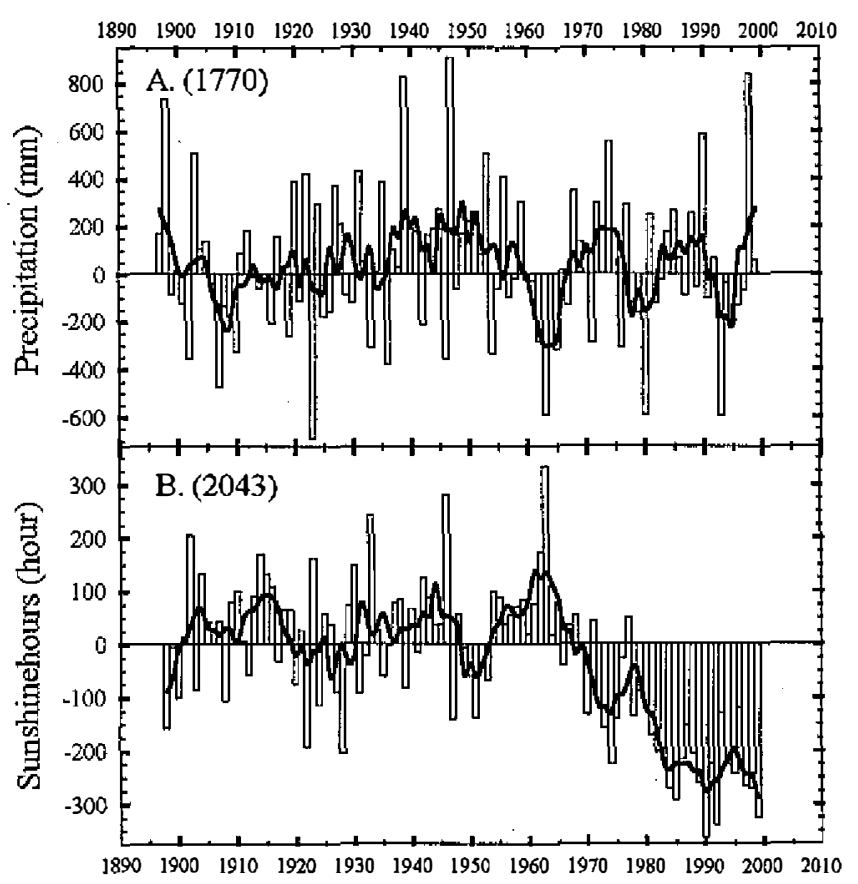

Fig. 5. Comparison of average annual precipitation to the average annual sunshine duration observed at eight long-term stations.

are highly unlikely caused by any drift in the instrument precision. On the other hand, there is little doubt that some of the stations suffered certain degree of long-term drift in the precision of instrument due to lack of calibration and maintenance. In fact, some of the differences among different stations are very likely the result of drifts in the instrument precision and/or differences in the quality of measurements.

As mentioned earlier, wends of sunshine duration observed at Tawu and Lanyu (Figs. 6ab) are qualitatively different from those of the other 16 stations. We don't have any definitive explanation for why Tawu and Lanyu should be different from the other 16 stations. Drift of the instrument precision certainly could contribute to the problem. If any drift could happen, it would more likely have happened at these two stations as they are smaller stations and have relatively short records. Moreover, unlike the other 16 stations, the two stations changed their instruments between 1971 and 1991, a critical time for the detection of trends after 1960.

\section{DISCUSSIONS}

Changes in sunshine duration of the four regimes after 1960 appear to be proportional to the emissions of air pollutants in those regimes. The largest reduction occurs in the first regime, i.e. the most polluted, and the smallest reduction occurs in the off-coast regime. However, quantitatively differences in the reductions among different regimes are substantially smaller than the differences in the AOD values of the corresponding stations. For example, 
(a)

\section{Tawu}

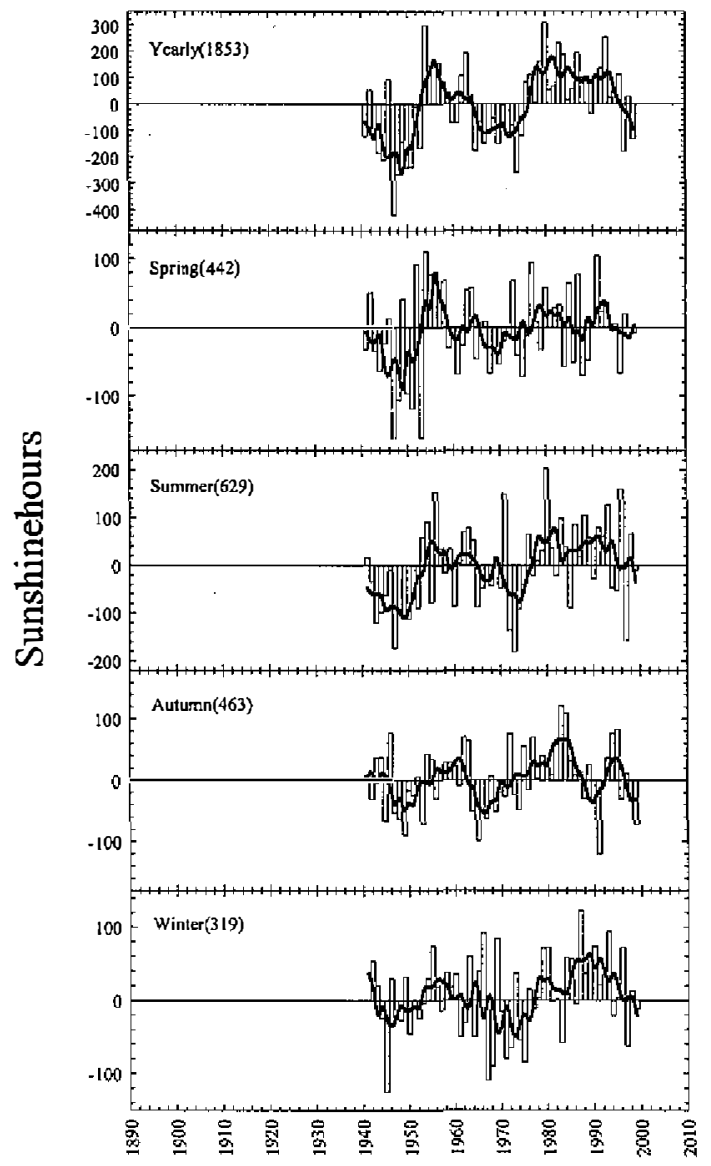

(b)

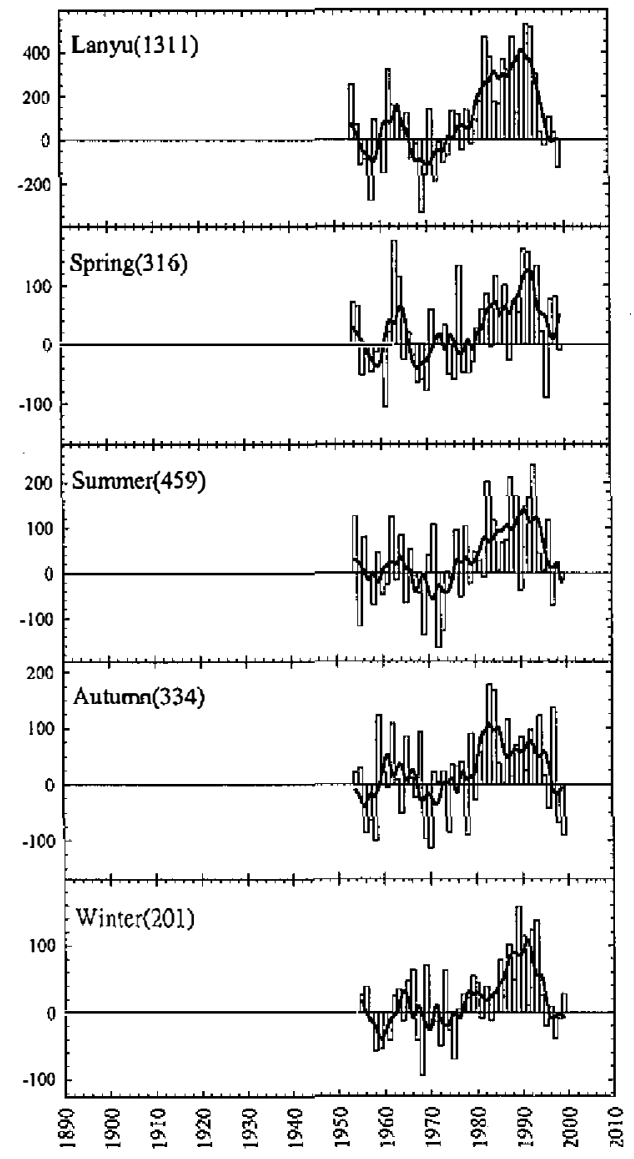

Figs. $6 a-b$. Annual and seasonal averages of sunshine duration at Tawu and Lanyu stations, respectively. Symbols are the same as those of Fig. 2.

if we take the 1961-1970 average values of sunshine duration as the bases that represent the values before significant emissions of air pollutants in Taiwan (see Fig. 3), the 1990-1999 average values are reduced by $16.1 \%, 15.1 \%, 13.3 \%$ and $11.8 \%$, respectively for the four regimes. In comparison the difference in AOD values between the first regime and the fourth is usually greater than a factor of 2 (Li 2002).

As discussed earlier, contribution of Taiwan's emissions to the air pollutant levels at the fourth regime stations (off-coast stations) should be negligible compared to the first and second regimes, especially in winter and spring when the influence of the winter monsoon dominates. Yet the reduction in sunshine duration of the fourth regime is more than two thirds of and has similar patterns as those of the first and second regimes. This suggests that the direct effect of Taiwan's local pollution sources contributes to less than one third of the reduc- 
tions of sunshine duration in the first and second regimes. This is also supported by the relatively large reductions in sunshine duration in the third regime in comparison to the first and second regimes.

The above conclusion becomes more evident when individual stations are examined. The clean site mentioned earlier at the southern tip of Taiwan, Hengchun (Fig. 7), is a good example. With an average PM10 concentration of about $20 \mu \mathrm{g} / \mathrm{m}^{3}$, Hengchun is a factor of more than 3 less than the PM10 concentrations of the first regime. The difference would be even greater if the anthropogenic components of PM10 are compared. However, the difference between the reductions of sunshine duration at Hengchun (Fig. 7) and those of the first regime (Fig. 4a) is negligible. In fact, yearly and seasonal reductions at Hengchun are essentially identical to those of Tainan, the large city closest to Hengchun. This is demonstrated in the excellent correlations (with slope close to 1) between percentage reductions of sunshine duration at Tainan and those at Hengchun for four seasons (Fig. 8), where the percentage reduction is calculated for each year after 1970 by using the 1961-1970 average as the base. Clearly, local concentration of aerosols is not in control of the reduction in sunshine duration at either Hengchun or Tainan. Further support of this notion is provided by the fact that the $2.4 \mathrm{~km}$ Alishan station has nearly the same reduction as low altitude stations of the first and second

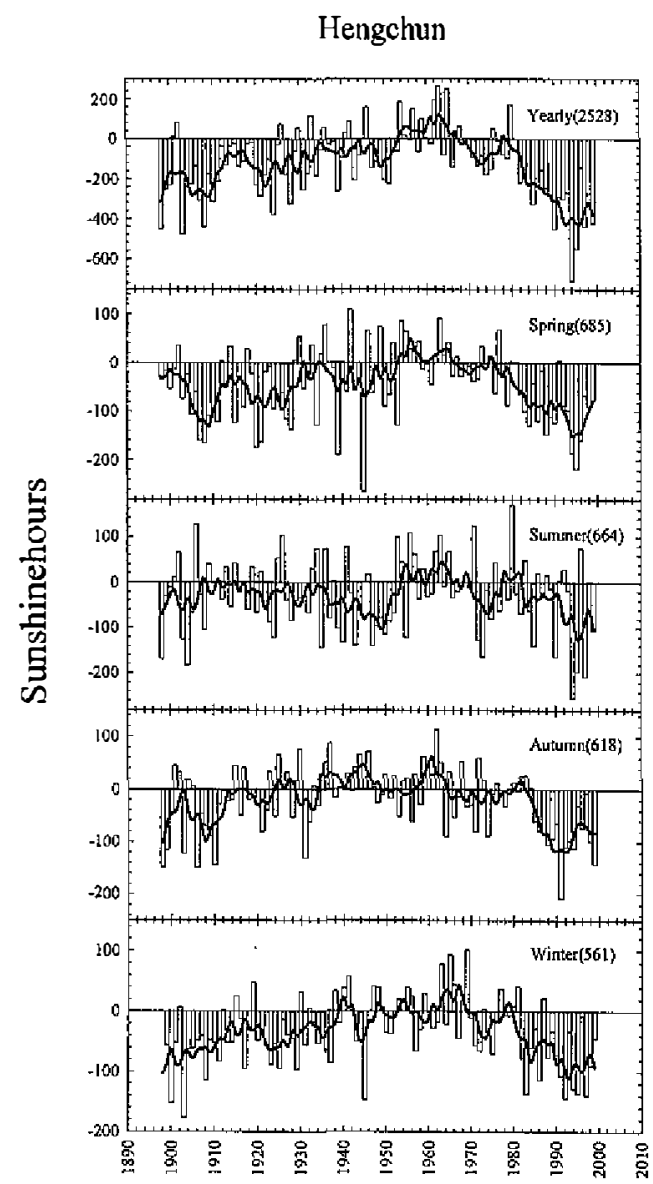

Fig. 7. Annual and seasonal averages of sunshine duration at Hengchun. Symbols are the same as those of Fig. 2. 

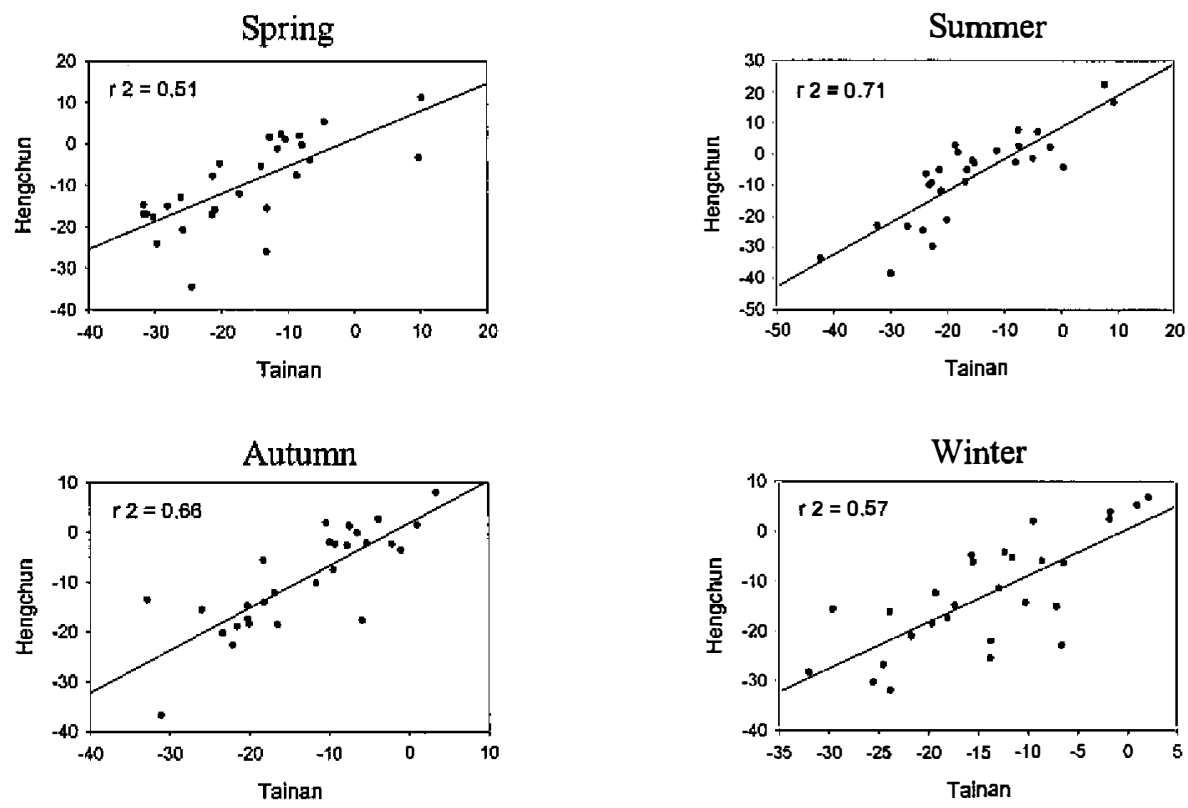

Fig. 8. Correlations between percentage reductions of sunshine duration at Tainan and those at Hengchun for four seasons, the percentage reduction is calculated for each year after 1970 by using the 1961-1970 average as the base value.

regimes. Although there is no PM10 observation at Alishan, the station is known to be isolated from any significant influence of local sources of aerosols.

In a systematic analysis of the correlations among reductions of sunshine durations at different stations, some intriguing patterns that can have important implications on the cause (s) of the reduction in sunshine duration starts to emerge. First, stations adjacent to each other tend to have similar reductions in sunshine duration with explained variances $\left(\mathrm{r}^{2}\right)$ usually greater than 0.6 , sometimes as high as 0.8 . In addition, most of the slopes of the linear regressions are close to one, particularly for those eight long-term stations which are likely to have better quality control in their measurements than other stations. Although these patterns are expected between stations with similar environments, e.g. large urban center pair Taipei-Taichung (Fig. 9), and median city pair Hualien-Taitung (Fig. 10), the close similarity in both variabilities and absolute values between urban and clean station pairs such as Taipei-Pengchiayu (Fig. 11), Taichung-Alishan (Fig. 12), and Tainan-Hangchun (Fig. 8) is a very suggestive surprise. It clearly suggests that the proximity in location is more important than levels of local pollutants in controlling the degree of correlation. This is evident by the fact that Taipei and Pengchiayu have a significant better correlation than Taipei and Tainan (not shown). Thus, the direct scattering by over head column aerosols (including those from surface sources and aircraft) can be ruled out as the major cause of the reduction in sunshine duration because values of the AOD over large urban areas (e.g. Taipei) are expected and have been shown to be considerably greater than those over remote areas such as Pengchiayu ( $\mathrm{Li} 2002)$. 

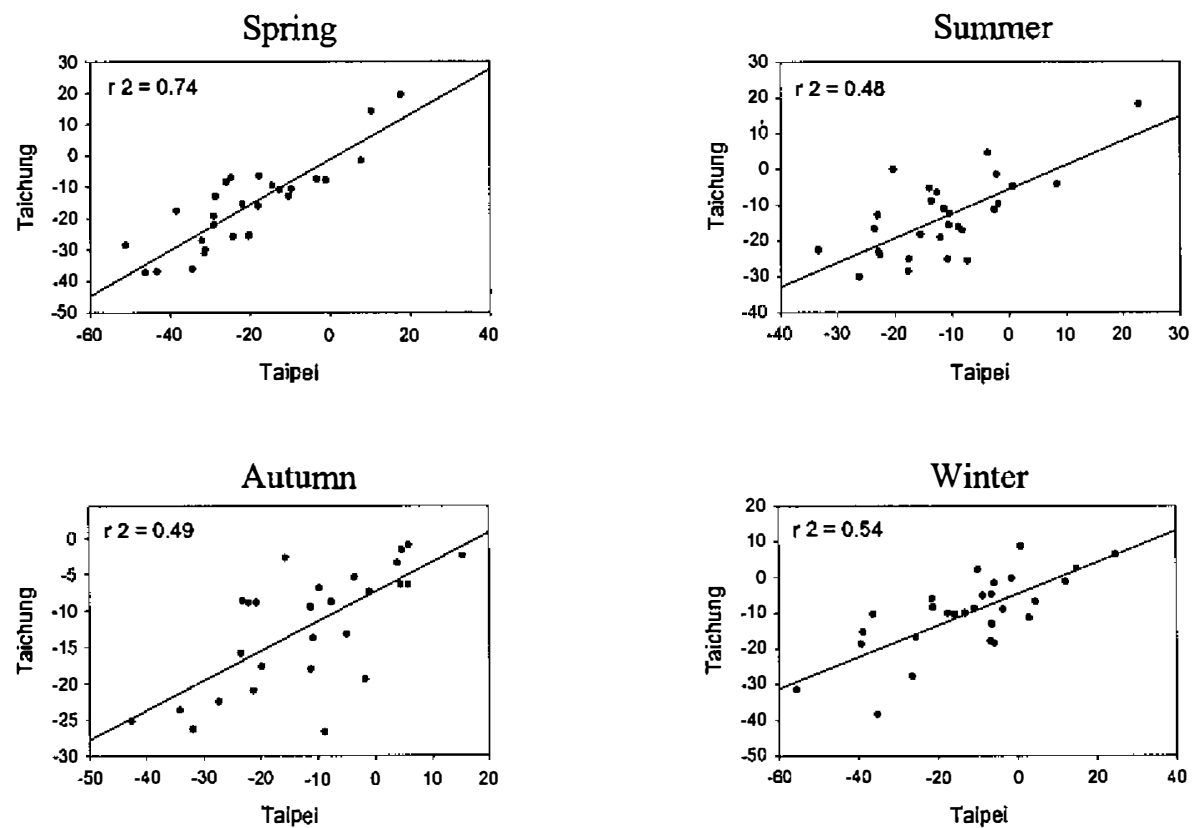

Fig. 9. Same as Fig. 8 except for Taipei and Taichung.
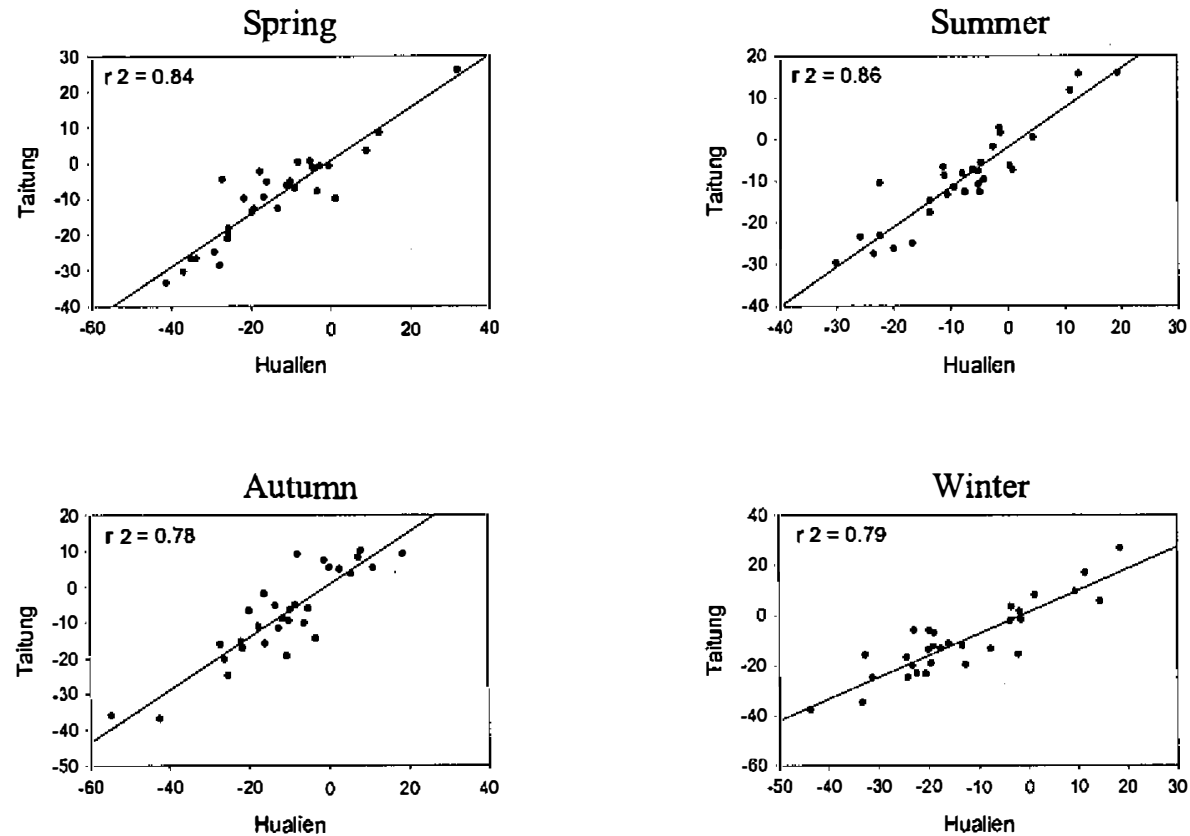

Fig. 10. Same as Fig. 8 except for Hualien and Taitung. 

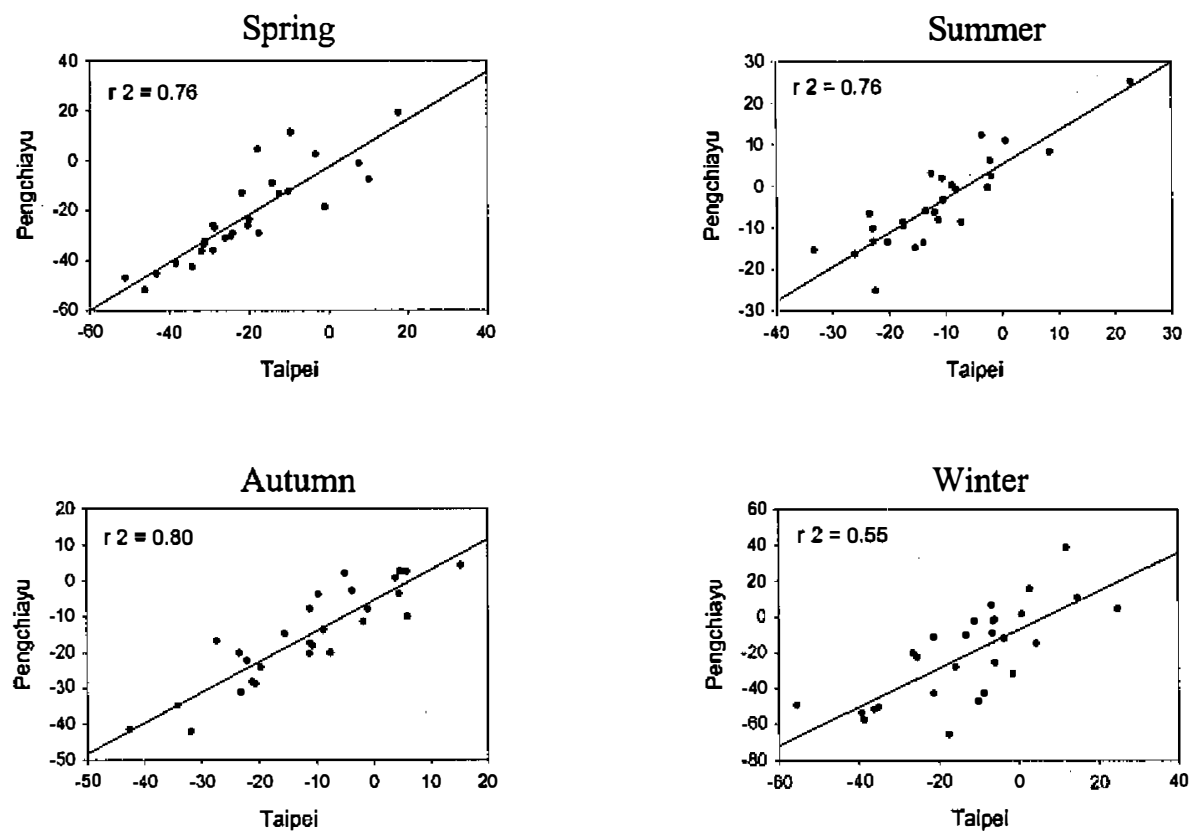

Fig. 11. Same as Fig. 8 except for Taipei and Pengchiayu.
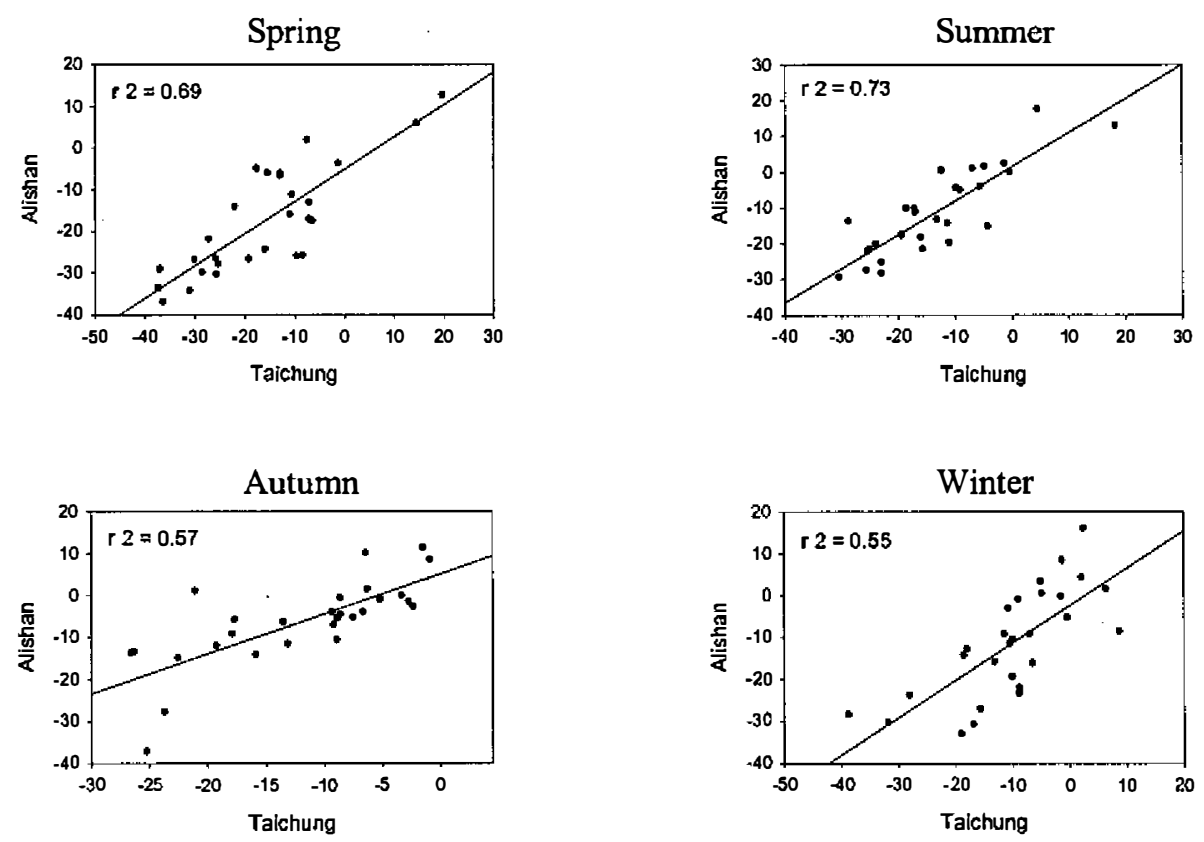

Fig. 12. Same as Fig. 8 except for Taichung and Alishan. 
The good correlation between various pairs of stations mentioned above can be linked together throughout Taiwan and her surrounding islands by correlating stations adjacent to each other, suggesting the major cause is a regional scale phenomenon covering all the stations discussed above. Altitude-wise we note that the Central Mountain Range does not block off the correlation as $\mathrm{r}^{2}$ is about 0.6 between the two stations Hualien-Taichung across the Central Mountain Range. Furthermore, very good correlation $\left(r^{2} \approx 0.7\right)$ has been found between the two mountain stations Alishan and Yushan. Thus the major contributor to the reduction in sunshine duration must be above Yushan or $3.85 \mathrm{~km}$. Since in winter and spring the prevailing winds above $3.85 \mathrm{~km}$ is westerly with a wind speed on the order of $100 \mathrm{~km} / \mathrm{hr}$, it is reasonable to expect that some of the regions upwind of Taiwan, namely southern China, Southeast Asia, and India, would suffer a similar reduction in sunshine duration. Li et al. (1998) found that there had been a significant reduction (about 10\%) in average surface solar insolation (including both direct and diffuse solar radiation) over most of China from 1970 to 1990. In this context, we note that as developing countries, anthropogenic emissions in China, Southeast Asia, and India have increased significantly since 1970's.

With the elimination of the direct scattering by aerosols, what is left as possible primary causes of the reduction in sunshine duration? There are two possibilities. In addition to the above-mentioned aerosol effect on clouds, an increase in fogs is a possibility. The latter can be ruled out readily because the observed frequencies of fogs have been decreasing substantially at most of meteorological stations in Taiwan since the 1960's. We don't know the exact reason of the decrease in the frequency of fogs. It probably has to do with a decrease in relative humidity as a result of an increase in near surface temperature, particularly during the night. This will be the subject of a future study.

A logical and most likely candidate of the primary contributor(s) to the reduction in sunshine duration is an increase in regional scale clouds and/or cloud albedo as a result of increasing anthropogenic emissions of aerosols. (Hereon for simplicity we'll omit citing cloud albedo, any change in clouds should be regarded as changes in both clouds and cloud albedo. This is justified because, as discussed in the introduction, an increase in clouds due to aerosols is accompanied by an increase in cloud albedo.) In spite of the subjective nature and well-known large uncertainty in the observations of clouds discussed earlier, for completeness we have examined observations of clouds at the long-term meteorological stations for possible trends. As expected the result is inconclusive as no significant trend is found. Clearly the uncertainty in the semi-quantitative naked-eye observation of clouds is too large to detect the trends on the order of $10 \%$ discussed here.

Without useful information from the direct observations of clouds, we need to look into other evidence that might provide independent support of the increase in regional scale clouds. Hansen et al. (1995) made a comprehensive modeling study of DTR and found that an increase in clouds was essential to account for a significant decrease in DTR observed over major continents (Karl et al. 1993; Zheng et al. 1997). Figure 13 depicts the average of observed DTR at the eight long-term stations. The figure shows a gradual decrease of DTR of about $0.4 \mathrm{~K}$ from 1930 to 1970 , a result of a persistent increase of nighttime minimum temperature and a nearly constant daytime maximum temperature. This is consistent with the decrease observed over major continents. A more important feature in the figure, however, is the dras- 


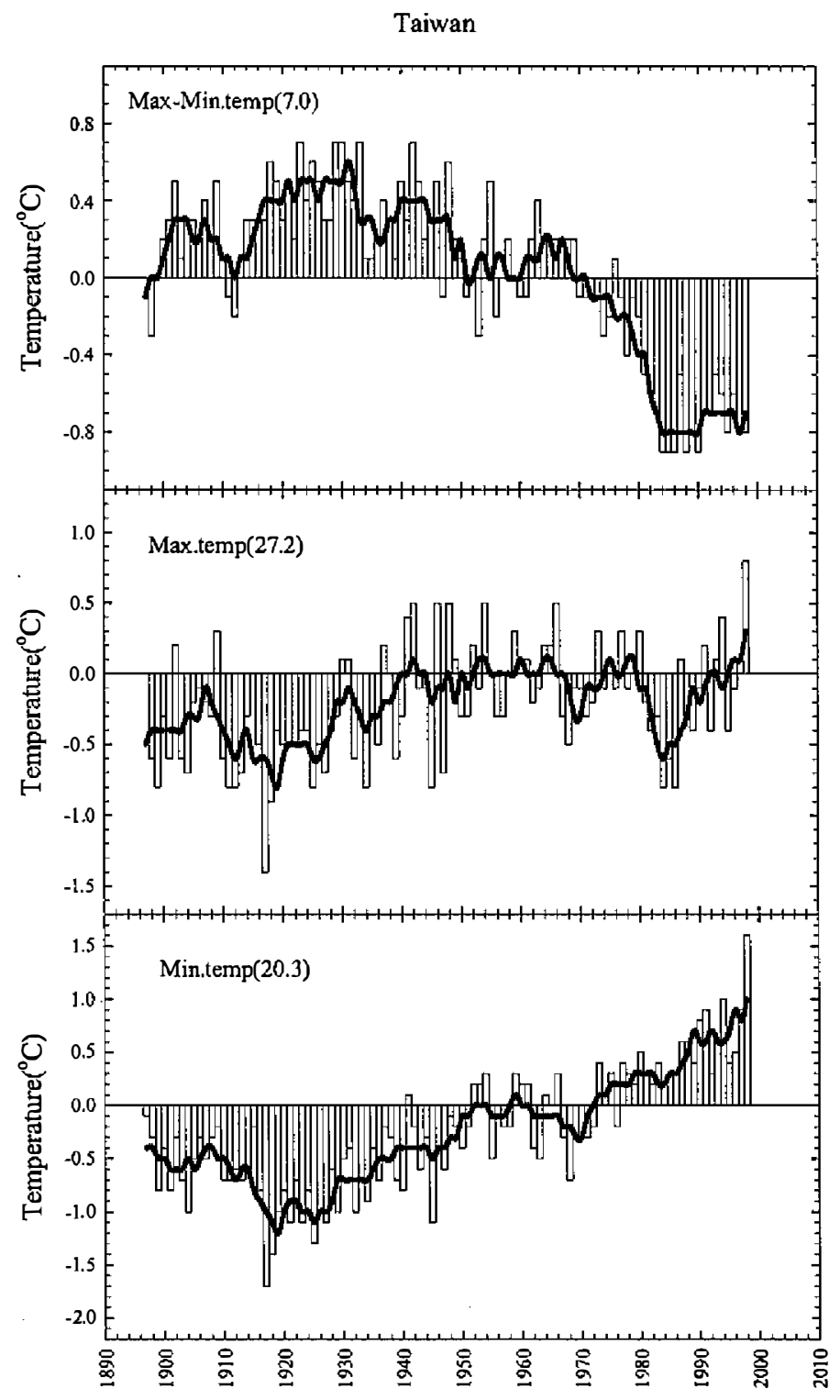

Fig. 13. Annual average of daily temperature minimum (lower panel), annual average of daily temperature maximum (middle panel), and their difference, i.e. the diurnal temperature range (top panel).

tic decrease of about $0.8 \mathrm{~K}$ from 1970 to 1984 , and then leveling off after 1984. The decrease and leveling-off are remarkably similar to those of the sunshine duration (Fig. 2). This provides an independent albeit indirect support for the increase in regional scale clouds as the major cause of the reduction of sunshine duration.

Hsu and Chen (2002) noticed the greater increase in regional temperature and believed 
that fluctuations in large-scale circulation could be a major cause. This could be part of the reason that the increase in nighttime minimum temperature in Taiwan since 1920 is about twice as large as the global average value. Nevertheless, the fluctuations in large-scale circulation need to be accompanied by an increase in regional-scale clouds in order to account for the decrease in DTR, especially after the 1970's.

Our conclusion that the major cause of the reduction in sunshine duration is an increase in regional scale clouds as a result of increasing anthropogenic emissions of aerosols is based on three major points. The first is a generally accepted aerosol-cloud hypothesis. The second is the consistency in the timing of regional anthropogenic emissions of aerosols (including Taiwan and the upwind areas) and that of the reductions in sunshine duration and in DTR. The third point is the elimination of other potential contributors. Considerable uncertainty remains in the conclusion because there is no direct observation of an increase in clouds, nor is there a proof of direct link between aerosols and clouds in this study. Thus we can't rule out that the increase in regional scale clouds is a result of some changes in large-scale circulation. We can, however, argue against this notion by pointing out that there is no compelling hypothesis about the increase in clouds as a result of the changes in large-scale circulation, nor is there a strong argument for the timing of the changes in large-scale circulation to coincide with the reductions in sunshine duration. In this context, we would like to point out that large changes have occurred in the environment in Asia over the last few decades, including increases in air pollutants and land-use changes. Theses changes are all potential contributors to the reduction in sunshine duration discussed here and need to be carefully studied. For example, after the submission of the first version of this paper, a recent publication by Menon et al. (2002) suggested black carbon aerosols over China and India could perturb the regional climate and result in an increase in cloud cover. Their results are consistent with the data presented here and therefore we acknowledge their proposed mechanism could also be a reasonable cause of the reduction in sunshine duration in Taiwan area. In fact, their mechanism is similar to our proposed cause, differing only in specific aerosol-atmosphere interaction processes of which relatively large uncertainty remains in the understanding.

The strong westerlies above $3.85 \mathrm{~km}$ in spring and winter as well as the reductions over off-coast islands imply that the source(s) of anthropogenic aerosols is from areas upwind of Taiwan. Climatological streamlines in winter and spring indicate that southern China, Southeast Asia, India and regions further upwind are all possible candidates. The prevailing wind above $3.85 \mathrm{~km}$ becomes southeasterly and much weaker in summer and fall, allowing significantly more time for emissions from Taiwan to interact with high clouds. Thus emissions of aerosols from western Taiwan in summer and fall can become a major contributor to the increase in clouds over the entire region around Taiwan. Contributions from emissions of different regions can be a major factor that leads to the seasonal variations observed in the reductions of sunshine duration.

\section{OTHER POTENTIAL RAMIFICATIONS}

As hypothesized by Warner and Twomey (1967) that the large number of anthropogenic $\mathrm{CCN}$ could generate smaller cloud droplets and slow down collision and coalescence growth 
of precipitation. Thus, the precipitation would be delayed and the cloud water content would increase. Since the water has to precipitate out eventually one would expect the precipitation intensity to increase. Indeed, this phenomenon can be seen in Fig. 14, which depicts the average precipitation, average number of rain hours, and the average precipitation intensity for all 13 stations in the first three regimes. The average precipitation intensity is calculated by dividing precipitation rain raining time for each hour at each station and then averaged over a year and the 13 stations. The variabilities in the precipitation and rain hours are significantly reduced when their ratio (i.e. the precipitation intensity) is calculated. This is expected

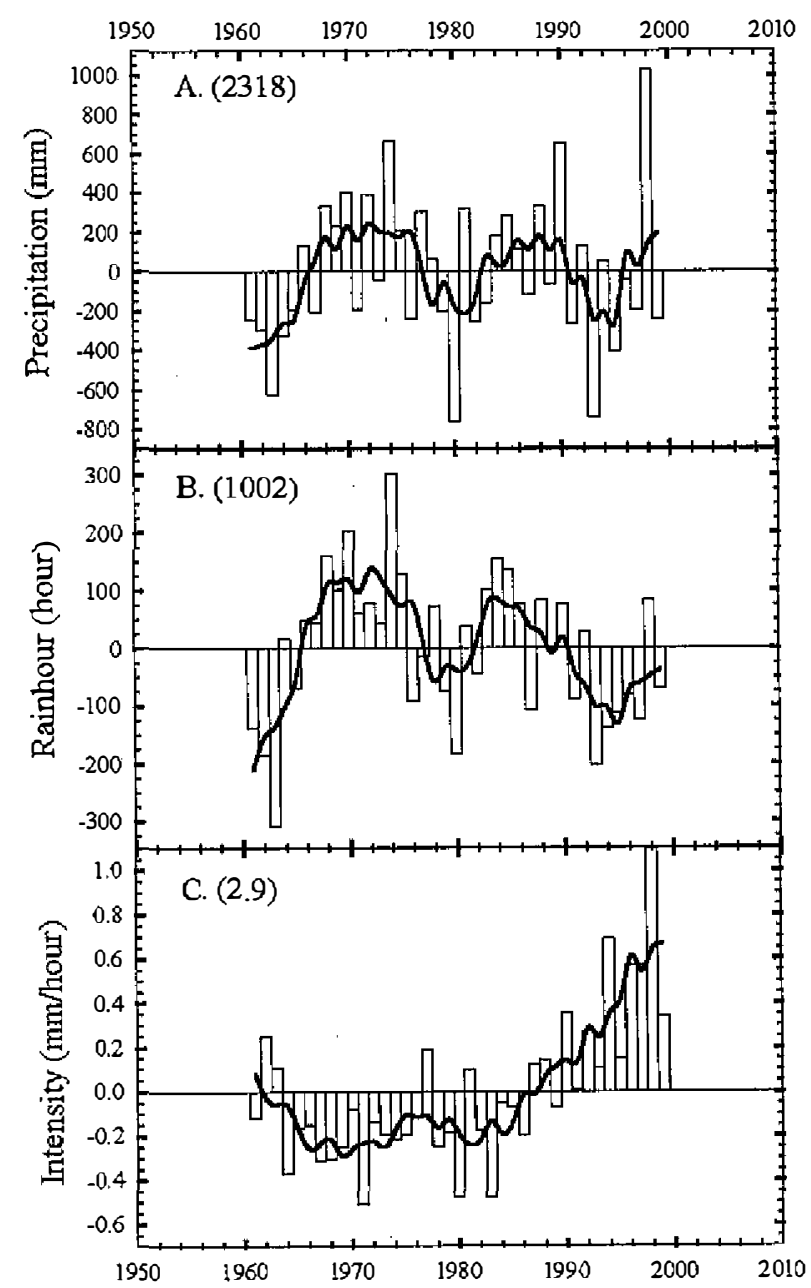

Fig. 14. Annual average precipitation for all 13 stations of first three regimes (top panel). The annual rain hours are shown in middle panel. The lower panel shows the precipitation intensity (see text about how is it evaluated). The zero lines represent the average values as shown inside the parentheses. 
and reassuring because the precipitation and rain hours are expected to be well correlated with each other. The reduced variability is important as it allows one to see readily in Fig. 14 that the precipitation intensity has increased significantly after 1980. The increase is clearly the result of a significant decrease in rain hours after 1980 while the precipitation remained about the same during that period. The average value of last five years is about $25 \%$ higher than the average value between 1961 and 1980 .

The data started in 1961 because hourly data was not available for most of the stations before that year. Daily data did go back to about 1900 for those eight long-term stations (Wu 1992). We have made similar analysis of those data and found no change in precipitation intensity before 1960 that is as large as the increase after 1980, reinforcing the notion that the increase is likely due to anthropogenic activities rather than natural variability.

A $25 \%$ increase in precipitation intensity is a very large change and certainly can have serious adverse impacts on the hydrological cycle and even the whole ecosystem. One obvious impact is to increase the probability of flooding. In this regard, one can't help but suspect that this impact might have some contribution to the severe floods in recent years in Taiwan. However, the majority of the severe floods in Taiwan are associated with typhoons. In addition to extremely strong winds, huge amount of water vapor, clouds, and rain, typhoons are expected to incorporate a large number of sea-salt aerosols. As a result, typhoons should be saturated with CCN and thus anthropogenic aerosols may not any significant effect on the clouds in typhoons. Obviously, a spectral analysis of the long-term changes in precipitation intensity and an analysis of precipitation associated with typhoons may shed some light into this problem. We have made some preliminary analyses along these lines. The trends mostly appear in light and medium precipitation. No significant trend has been found in heavy rain. In this regard, we note that the interaction between aerosols and clouds involves extremely complex chemical and physical processes. The effect on precipitation intensity requires considerable more researches before a reasonable understanding can be achieved.

Although we believe that the increase in precipitation intensity and the decrease in sunshine duration are both caused by the indirect effect of anthropogenic aerosols, the two changes have different characteristics. For example, we notice that the increase in precipitation intensity does not occur in off-coast islands, nor does it occur in winter. At this moment, we don't have a good explanation of the differences between changes in precipitation intensity and sunshine duration. Moreover, the changes in sunshine duration, DTR, clouds, precipitation intensity, and other parameters of regional climate are very likely inter-related and some even tightly coupled. Consequently, the cause-effect relationship can be extremely difficult to untangle. A comprehensive statistical analysis of existing meteorological data in conjunction with a well-designed modeling and field experiment could be very helpful in understanding this problem.

\section{CONCLUSIONS}

We have examined the long-term records of meteorological parameters of Taiwan to study causes and implications of a decreasing trend in sunshine duration observed during Taiwan's rapid economic developing period that started in the early 1960's. Significant reductions in 
sunshine duration have been found at 16 out of 18 stations analyzed. The two stations that failed to detect the reduction probably had an instrument problem(s). They were the only stations that changed instruments between 1971 and 1991, a crucial time for the detection of the decreasing trends.

Although the largest reductions of about 16\% (difference between the 1990-1999 average and the 1961-1970 average) are found in three urban centers, in-depth analysis shows that the reductions are quite uniform and well correlated among stations throughout Taiwan and her surrounding islands. Differences between the reductions in urban centers and those of rural, remote, and mountain stations are less than $4 \%$. These differences are substantially smaller than the differences in observed aerosol optical depths among those stations, suggesting that direct scattering by aerosols is not the major cause of the reductions. Furthermore, fogs are also ruled out to have any significant contribution to the reduction because the frequency of fogs has been decreasing throughout Taiwan since the 1960's. This leaves the increase in regional scale clouds and/or cloud albedo due to increasing anthropogenic emissions of aerosols as the only logical candidate of the primary contributor(s) to the reduction in sunshine duration. This increase in regional clouds is also supported by the large reduction in the diurnal temperature range in Taiwan ielative to other parts of the globe since about 1970.

Seasonal variations of the reduction in sunshine duration are similar at different stations. Altitude-wise, similar reductions also occur at high altitude stations, namely Alishan $(2.4 \mathrm{~km})$ and Yushan $(3.85 \mathrm{~km})$, suggesting that the cause of the reductions is at altitude above $3.85 \mathrm{~km}$. The strong westerlies above $3.85 \mathrm{~km}$ in spring and winter as well as the reductions over offcoast islands imply that the source(s) of anthropogenic aerosols is from areas upwind of Taiwan. Climatological streamlines in winter and spring indicate that southern China, Southeast Asia, India and regions further upwind are all possible candidates. The prevailing wind above 3.85 $\mathrm{km}$ becomes southeasterly and much weaker in summer and fall, allowing significantly more time for emissions from Taiwan to interact with high clouds. As a result emissions of aerosols from western Taiwan can become a major contributor to the increase in clouds over the entire region around Taiwan in summer and fall.

Beside the reduction in sunshine duration, an increase in clouds/cloud albedo can also leads to a decrease in DTR. These changes may also be linked to decreases in near surface relative humidity and occurrence of fogs. Finally and probably the most serious change found so far is the increase in the intensity of precipitation since about 1980, a result of decreasing rain hours and relatively constant amount of precipitation. We believe that the decrease of rain hours is consistent with the hypothesis forwarded by Warner and Twomey (1967) that the increasing number of anthropogenic $\mathrm{CCN}$ would generate smaller cloud droplets, slow down collision and coalescence growth of precipitation, and increase lifetime of clouds.

The changes discussed above can have profound and serious implications to the regional climate and ecosystem. In particular, the decrease in rain hours and the increase in precipitation intensity can have a severe adverse impact on the hydrological cycle, e.g. increases in river run-off and floods. While there is no hard evidence linking recent catastrophic floods in Taiwan to the increase in precipitation intensity found here, the problem is of such great importance that a comprehensive investigation is imperative.

Although it is difficult to establish the causal relationship for all the changes mentioned 
above, there is little doubt that the changes are inter-related and they are likely to contribute or to be coupled to changes in other parameters of regional climate. A comprehensive analysis of existing meteorological data in conjunction with modeling and a well-designed field experiment are essential to unveiling the complexity in the causal relationship, understanding the key controlling processes, and evaluating the environmental impacts of these changes.

Acknowledgement We appreciate helpful discussions with Professors C-T Lee and George $\mathrm{N}-\mathrm{H}$ Lin of National Central University, and George T-J Chen, J-P Chen, Ho Lin, P-H Lin and $\mathrm{M}-\mathrm{C}$ Wu of National Taiwan University. The work is supported in part by the Theme Research Proposal to Academia Sinica entitled "Particulate Matter and its Environmental Impacts in Taiwan", and by the National Science Council proposal entitled "A Research Program at the Lanyu Atmospheric Baseline Station". Finally, we thank three anonymous reviewers whose careful reviews and comments have substantially improved this manuscript.

\section{REFERENCES}

Boucher, O., 1998: Is the Observed Trend in Cirrus Occurrence Due to Aviation? Note Interne du LOA No. 1, Laboratoire d'Optique Atmosphérique, UFR de Physique, Université de Lillie-I, Villeneuve d'Ascq, France, 17pp.

Boucher, O., 1999: Influence of air traffic on cirrus occurrence. Nature, 397, 30-31.

Changnon, S. A., Jr., 1981: Midwestern cloud, sunshine and temperature trends since 1901: Possible evidence of jet contrail effects. J. Appl. Meteor., 20, 496-508.

Coakley, J. A., R. L. Bernstein, and P.A. Durkee, 1987: Effect of ship-tack effluents on cloud reflectivity. Science, 237, 1020-1022.

EPA-Republic of China, 2000: Air Quality Protection Over the Last 25 Years, pp. 385, Published by the Environmental Protection Administration, Taipei, Taiwan, Republic of China.

Frankel, D., K.-N. Liou, S. C. Ou, D. P. Wylie, and P. Menzel, 1997: Observations of cirrus cloud extent and their impacts to climate. Proceedings, Ninth Conference on Atmospheric Radiation, February 2-7, 1997, Long Beach, CA, Amer. Meteor. Soc., 414417.

Hansen, J., M. Sato, and.R. Ruedy, 1995, Long-term changes of the diurnal temperature cycle: implications about mechanisms of global climate change. J. Atmos. Res., 37, 175-209.

Hsu, H-H, and C-T Chen, 2002: Observed and projected climate change in Taiwan. Meteorology and Atmospheric Physics, 79, 87-104.

Husar, R. B., J. M. Prospero, and L. L. Stowe, 1997: Characterization of tropospheric aerosols over the oceans with the NOAA Advanced Very High Resolution Radiometer optical thickness operational product. J. Geophys. Res., 102, 16889-16909.

Karl, T. P. Jones, R. Knight, G. Kukla, N. Plummer, V. Razuvayev, K. Gallo, J. Lindseay, R. Charlon, and T. Peterson, 1993: A new perspective on recent global warming: asymetric trends of daily maximum and minimum temperature. Bull. Amer. Meteor. Soc., 74(6), 1007-1023.

Li, C., 2002: Remote sensing of aerosol optical depth by MODIS and its application in the 
regional environmental air pollution studies, $\mathrm{PhD}$ thesis, Peking University.

$\mathrm{Li}$, Xiaowen, W. Li, and X. Zhou, 1998, Changes in solar radiation in China over the last 30 years. Quarterly Journal of Applied Meteorology, 9, 24-31.

Liepert, B., 1997: Recent changes in solar radiation under cloudy conditions. Int. J. Climatology, 17, 1581-1593.

Liou, K.-N., S. C. Ou, and G. Koenig, 1990: An investigation of the climatic effect of contrail cirrus. In U. Schumann(ed.): Air Traffic And the Environment: Background, Tendencies, and Potential Global Atmospheric Effects. Springer-Verlag, Berlin, Germany, pp. 154169.

Menon, S., J. Hansen, L. Nazarenko, and Y. Luo., 2002: Climate effect of black carbon aerosols in China and India. Science, 297, 2250-2253.

Minnis, P., D. F. Young, D. P. Garber, L. Nguyen, W. L., Smith, Jr., and R. Palikonda, 1998a: Transformation of contrails into cirrus during SUCCESS. Geophys. Res. Lett., 25, 11571160.

Radke, L. F., J. A. Coakely, Jr., and M. D. King, 1989: Direct and remote sensing observations of the effects of ships on clouds. Science, 246, 1146-1148.

Rebetez, M., and M. Benison, 1998. Changes in sunshine duration are correlated with changes in daily temperature range this century: An analysis of Swiss climatology data. Geophys Res. Lett., 25, 3611-3613.

Twomey, W., 1974: Pollution and the planetary albedo. Atmos. Environ., 8, 1251-1256.

Twomey, S., M. Piepgrass, and T. L. Wolfe, 1984: An assessment of the impact of pollution on global albedo. Tellus, 36B, 356-366.

Warner, J., and S. Twomey, 1967: The production of cloud nuclei by cane fires and the effects on cloud droplet concentration. J. Atmos. Sci., 24, 704-706.

Wu, M. C., 1992: Climate variation in Taiwan-temperature and precipitation. Atmospheric Science, 20, 295-318.(in Chinese)

Zheng, X. G., R. E. Basher, C. S. Thompson, 1997: Trend detection in regional mean temperature series: maximum, minimum, mean, diurnal range, and SST. J. Climate, 10(2), 317-326. 